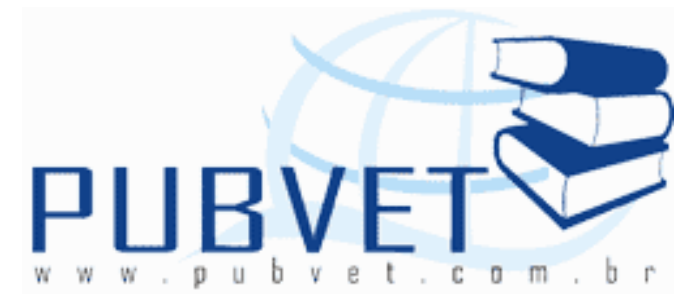

PUBVET, Publicações em Medicina Veterinária e Zootecnia.

\title{
Uso de indicadores nos estudos da nutrição animal
}

\begin{abstract}
Andrezza Kyarelle Bezerra de Moura ${ }^{1}$, Renata Nayhara de Lima ${ }^{2}$, Kátia Tatiana de Lima Lopes ${ }^{1}$, Jacinara Hody Gurgel Morais ${ }^{2}$, Maria Vivianne Freitas Gomes de Miranda ${ }^{1}$, Patrícia de Oliveira Lima ${ }^{3}$

${ }^{1}$ Mestranda do Programa de Pós-graduação em Ciência Animal - UFERSA
${ }^{2}$ Doutoranda do Programa de Pós-graduação em Ciência Animal - UFERSA
${ }^{3}$ Professora Adjunta - Departamento de Ciências Animais - UFERSA
\end{abstract}

\section{Resumo}

A quantidade de alimento ingerido por um animal e o quanto ele absorve de nutrientes é essencial para que se façam alterações a respeito do alimento e da resposta do animal, assim o uso de indicadores é uma das ferramentas que facilita avaliar determinados parâmetros fisiológicos e nutricionais. Os indicadores são divididos em dois grandes grupos, internos e externos, os mesmos podem ser adicionados à dieta ou fornecidos via oral ou ruminal aos animais. Para que uma substância possa ser utilizada como indicador, deve atender a determinados critérios. Os indicadores são substâncias capazes de colaborar com inúmeros aspectos nas áreas da alimentação e da nutrição animal, principalmente em situações a pasto. Logo, para o uso dos mais diversos indicadores existentes que são utilizados para estimar taxas de passagem, consumo, produção fecal e de digestibilidade, devem ser estabelecidos critérios, como facilidade de uso e determinação, que norteiem a 
MOURA, A.K.B. et al. Uso de indicadores nos estudos da nutrição animal. PUBVET, Londrina, V. 7, N. 24, Ed. 247, Art. 1634, Dezembro, 2013.

decisão pelo indicador que melhor se adapte aos parâmetros a serem avaliados.

\section{Use of indicators in studies of animal nutrition}

\section{Abstract}

The quantity of food ingested by an animal and how much it absorbs nutrients is essential to make changes regarding food and the animal's response, so the use of indicators is one of the tools that facilitate evaluating determined physiological and nutritional parameters. The indicators are divided into two large groups, internal and external, they can be added to the diet or given orally or ruminal animals. For a substance to be used as an indicator, must meet certain criteria. Indicators are substances capable of collaborating with innumerable aspects in the areas of food and animal nutrition, especially in situations at pasture. Thus, the use of various existing indicators are used to estimate passage rates, consumption, production and fecal digestibility, criteria should be established, as ease of use and determination to guide the decision by the indicator that best fits the parameters be assessed.

\section{INTRODUÇÃO}

A utilização racional dos alimentos evita o uso de nutrientes em excesso e, assim, reduz a excreção destes no meio ambiente, gerando maior lucratividade e sustentabilidade à atividade. Para se quantificar o valor nutritivo dos alimentos deve-se considerar o consumo, a digestão, e a utilização dos nutrientes, além da sua composição química. Conhecendo-se o consumo e a digestibilidade de um alimento é possível mensurar a quantidade de nutrientes absorvíveis presentes em um alimento. O consumo e a digestibilidade, portanto, são os dois principais componentes que determinam a qualidade de um alimento. Porém, a falta de métodos precisos para se 
MOURA, A.K.B. et al. Uso de indicadores nos estudos da nutrição animal. PUBVET, Londrina, V. 7, N. 24, Ed. 247, Art. 1634, Dezembro, 2013.

estimar o consumo de forragem ainda é limitado. Neste sentido, várias alternativas metodológicas continuam sendo propostas. Dentre as técnicas utilizadas pelos pesquisadores nos últimos anos, estão os indicadores (COLLET, 2011).

Indicadores são substâncias indigestíveis, normalmente de fácil determinação, podendo ser administradas com o alimento ou diretamente em algum segmento do aparelho digestório, sendo posteriormente identificados e quantificados nas fezes ou ao final do segmento em estudo (WARNER, 1981). Logo, indicador é o termo utilizado para denominar materiais usados na estimativa qualitativa ou quantitativa de fenômenos fisiológicos ou nutricionais relacionados à digestão. Um indicador, portanto, é um composto usado como monitor químico (hidrólise e síntese) e físico (fluxo) de aspectos de digestão e/ou metabólitos (OWENS \& HANSON, 1992).

Os indicadores são substâncias capazes de colaborar com inúmeros aspectos nas áreas da alimentação e da nutrição animal, principalmente em situações a pasto. Os estudos sobre os mesmos têm proporcionado ajustes nas metodologias de fornecimento (dose diária e tempo de estabilização), coletas (vezes por dia e número de dias) e análises (vícios de amostragem e procedimentos laboratoriais), tornando suas estimativas cada vez mais precisas (OLIVEIRA et al., 2012).

Os indicadores possuem grande aplicação nos estudos das taxas de passagem de líquidos e sólidos, consumo voluntário, produção fecal e digestibilidade de alimentos em animais em pastejo ou confinados (SALIBA, 1998).

Comparativamente com processos invasivos, os indicadores minimizam a interferência com os padrões de comportamento animal e simplificam os procedimentos, tendo em vista a não necessidade de utilização de cânulas reentrantes no trato digestivo, sacolas de coleta de fezes e até mesmo esvaziamento do trato digestivo ou abate dos animais (RODRIGUEZ et al., 2006). Este trabalho apresenta uma síntese sobre os princípios de utilização 
MOURA, A.K.B. et al. Uso de indicadores nos estudos da nutrição animal. PUBVET, Londrina, V. 7, N. 24, Ed. 247, Art. 1634, Dezembro, 2013.

dos indicadores e os últimos avanços obtidos em experimentos com nutrição de ruminantes.

\section{INDICADORES INTERNOS}

Os indicadores internos são constituintes naturais das dietas, tais como a sílica, a lignina, o cromogênio, a fibra em detergente neutro (FDNi) e a fibra em detergente ácido (FDAi) indigestíveis, a cinza insolúvel em ácido e os nalcanos (COLLET, 2011).

Os indicadores internos são constituintes da dieta que se apresentam inalterados através do trato gastrintestinal, e têm se constituído como alternativa ao método de coleta total e aos indicadores externos (ÍTAVO et al., 2002b). Os indicadores internos apresentam naturalmente algumas das características dos indicadores ideais, entre essas a ausência de influência negativa sobre os sistemas digestivos animal e microbiano, pelo fato de estarem presentes naturalmente nos alimentos (COLLET, 2011).

\subsection{Sílica}

A sílica tem a vantagem de não ser digerida e absorvida, porém o fato e existir no solo limita a sua utilização em maior escala, pois é difícil garantir que o animal ingira somente no alimento e não em outra fonte (ANDRIGETTO, 1981).

Estudos mostram que o valor da sílica como um indicador interno não tem sido muito acurado nos ensaios de pastejo, pois o animal consome grandes quantidades nesta condição (STREETER, 1969). Portanto, a contaminação com a sílica do solo é o principal fator que influencia negativamente o uso deste constituinte da planta. Jones \& Hadreck (1965), obtiveram estimativas confiável da digestibilidade usando determinação colorimétrica para a sílica, proposto por King et al. (1955), tomando precauções contra a contaminação. 
MOURA, A.K.B. et al. Uso de indicadores nos estudos da nutrição animal. PUBVET, Londrina, V. 7, N. 24, Ed. 247, Art. 1634, Dezembro, 2013.

\subsection{Lignina}

A lignina é um polímero de unidades de fenilpropanóides que ocorre na parede celular das plantas forrageiras. Teoricamente a digestibilidade da lignina é igual a zero (lignina verdadeira). Entretanto, em gramíneas jovens e em outras espécies com baixo conteúdo de lignina, pode-se encontrar uma aparente digestibilidade para lignina, o que resulta em erros na estimativa da digestibilidade da forrageira. A deficiência da recuperação da lignina nas fezes, é decorrente de alguns fatores, tais como: em gramíneas jovens a lignina possui menor grau de polimerização e os fragmentos de baixo peso molecular são absorvidos e excretados via urina; a lignina bruta pode sofrer contaminação de outros componentes do alimento (reação de Mailard); pode ocorrer formação de material fenólico solúvel, além de que,frações muito pequenas são perdidas durante o processo de filtragem (SALMAN et al., 2010).

Por outro lado, trabalhos apresentam a lignina como um indicador eficiente (PIAGGIO et al., 1991). Em dietas contendo altas quantidades de concentrado, os resultados não parecem satisfatórios, provavelmente em função do baixo teor de lignina existente (THONEY et al., 1979). O uso da lignina, em detergente ácido (LDA), apresenta a vantagem ser um método fácil de rápida análise, econômico e rotineiro em laboratórios de análise de alimentos. Recuperações positivas e incompletas foram relatadas por (FAHEY \& JUNG, 1983; VAN SOEST, 1994).

Segundo Fahey \& Jung (1983), revisando o uso da lignina como indicador, verificaram que a lignina foi digerida em rações contendo $100 \%$ de forragem e até $90 \%$ de concentrado, podendo, por conseguinte, ser usada como indicador somente quando apresentar evidências de sua alta recuperação fecal.

Existem vários fatores que afetam a recuperação da lignina. Muntifering (1982) citou as prováveis razões da ineficiência da recuperação da lignina: diferenciação dos monômeros fenólicos da lignina original (digestão 
MOURA, A.K.B. et al. Uso de indicadores nos estudos da nutrição animal. PUBVET, Londrina, V. 7, N. 24, Ed. 247, Art. 1634, Dezembro, 2013.

verdadeira); digestão aparente obtida pela formação de complexos solúveis lignina-carboidratos; destruição parcial da lignina fecal pelos reagentes usados nos métodos analíticos; e diferenças físicas e/ou químicas entre os alimentos e as fezes na natureza do material definido como lignina.

Em eqüinos, Fonnesbeck (1968) encontrou variações na digestibilidade da lignina em leguminosas, de $-15,60$ a 4,80\%, e em gramíneas, de 0 a 16,40\%. Maurício (1993) comparou os valores de digestibilidade de uma ração composta de feno de capim coast-cross e concentrado, estimados por meio da lignina e do óxido crômico, com o método de coleta total de fezes. Os resultados mostraram que a lignina e óxido crômico subestimaram os coeficientes de digestibilidade aparente da MS, PB, EB, FDN e FDA, devido às suas baixas recuperações. Resultados semelhantes foram obtidos por Machado (1992) com potros alimentados com diferentes combinações de cana-deaçúcar e capim-elefante, em que a lignina apresentou recuperação fecal média de $58,33 \%$, permitindo concluir que foi ineficiente para estimar a digestibilidade dos nutrientes em eqüinos.

\subsection{Cromogênio}

O cromógeno é um pigmento, produto da degradação da clorofila, utilizado como indicador interno em função de sua relativa indigestibilidade (KOBT \& LUCKEY,1972). A utilização de cromógenos propicia resultados muito variáveis e pouco confiáveis. O uso prático de cromógeno como um indicador interno é essencialmente limitado à forragem com alto conteúdo de clorofila, assim como forragens frescas. O método é empírico e requer padrões para análise de ensaio de digestão para forragem em estudo (VAN SOEST, 1994).

\subsection{Fibra em detergente neutro (FDNi) e ácida (FDAi) indigestíveis}

As frações que demonstraram maior potencial como indicadores são as fibras em detergente neutro (FDNi) e ácido (FDAi), (ZEOULA et al., 2002). De 
MOURA, A.K.B. et al. Uso de indicadores nos estudos da nutrição animal. PUBVET, Londrina, V. 7, N. 24, Ed. 247, Art. 1634, Dezembro, 2013.

acordo com Lippke et al. (1986), estudando o tempo de incubação para determinar a FDNi, observaram que, a partir de seis dias de incubação in vitro $(144$ h), o resíduo representa a porção indigestível do alimento. Tais resultados foram confirmados por Berchielli et al. (2000), que, ao compararem os indicadores internos FDNi e FDAi, concluíram que essas frações representam, de forma adequada, a porção indigestível do alimento.

Cochran et al. (1986) estudando estimativas de consumo por meio dos constituintes indigestíveis da parede celular observaram alta variabilidade nos dados estimados pela FDNi e FDAi, e não recomendaram a utilização da Lignina indigestível nestas estimativas. Estes dados também haviam sido apresentados por Fahey \& Jung (1983), que alertaram sobre os riscos das estimativas de consumo pela Lignina, recomendando a utilização deste indicador apenas quando os dados demonstrassem alta recuperação fecal.

Em um estudo sobre a composição de indicadores internos e seus potenciais para estimar a excreção fecal, Saliba et al. (1999) concluíram que os resultados médios obtidos pela FDAi foram semelhantes ao da coleta total de fezes. Berchielli et al. (2000) compararam as estimativas de consumo e digestibilidade a partir de indicadores internos (FDNi, FDAi, Lignina e Cinzas insolúvel em ácido) com a coleta total de fezes em machos cruzados, estabulados em baias individuais. Os autores testaram dois períodos de incubação (três e seis dias) e concluíram que apenas o FDNi e o FDAi incubados por seis dias estimaram adequadamente a digestibilidade e o consumo. Zeoula et al. (2002) trabalhando com ovinos estabulados e estudando a recuperação fecal dos indicadores internos, verificaram que tanto a FDNi estimou em $100 \%$ o volume de fezes (semelhante à coleta total) enquanto que FDAi superestimaram a produção de fezes, o que deixa dúvidas sobre possíveis interferências comportamentais e específicas entre os indicadores.

Contudo, Ferret et al. (1999) e Ítavo et al. (2002a) citam que a FDAi apresenta grande potencial como indicador para forragens em função do baixo custo e à facilidade metodológica. 
MOURA, A.K.B. et al. Uso de indicadores nos estudos da nutrição animal. PUBVET, Londrina, V. 7, N. 24, Ed. 247, Art. 1634, Dezembro, 2013.

\subsection{Cinza insolúvel em ácido (CIA) e cinza insolúvel em detergente ácido (CIDA)}

Resultados positivos para o uso desse indicador foram encontrados por vários autores (BERGERO et al., 2004). No entanto Sherrod et al. (1978) citam que o uso da CIA somente será adequado, quando sua participação na matéria seca da ração for superior a 3\%, em contraste com Thoney et al. (1979), que encontraram semelhança entre o método da coleta total de fezes e seu valor estimado pela CIA, esta última variando de 0,33 a 0,74\% da matéria seca da dieta. Thoney et al. (1985) concluíram que, se a dieta apresentar $0,75 \%$ ou mais da CIA na matéria seca, seu uso é seguro.

Em eqüinos, Sutton et al. (1977) não encontraram diferenças nos coeficientes de digestibilidade da energia bruta e do nitrogênio, estimados pela CIA HCl4N e pelo método de coleta total de fezes. Mais estudos realizados por Machado (1992), comparou a eficiência da $\mathrm{CIA} \mathrm{HCl}_{2} \mathrm{~N}$, cinza insolúvel em detergente ácido (CIDA), para estimar a digestibilidade dos nutrientes em eqüinos alimentados com diferentes combinações de capim-elefante e cana de açúcar, com o método de coleta total de fezes. O autor concluiu que tanto a CIA como CIDA mostraram-se eficientes para estimar a digestibilidade dos nutrientes em eqüinos, sendo os coeficientes de digestibilidade dos nutrientes obtidos por meio dos indicadores semelhantes àqueles determinados pelo método de coleta total de fezes.

A recuperação fecal dos indicadores CIA e óxido crômico em novilhos alimentados com rações contendo 30 ou $50 \%$ de concentrado, foi relatada por Fontes et al. (1996), os autores observaram valores médios de recuperação de CIA próximos de $100 \%$, independentemente do teor de concentrado na dieta, com o máximo de 105,1 e o mínimo de $102,4 \%$. Os teores de CIA nas rações foram de 2,7 e $1,1 \%$ para rações com 30 e $50 \%$ de concentrado respectivamente.

Zeoula et al. (2002) relataram que os trabalhos com CIA ou CIDA podem gerar estimativas diferentes dos valores reais, podendo ser consequência das 
MOURA, A.K.B. et al. Uso de indicadores nos estudos da nutrição animal. PUBVET, Londrina, V. 7, N. 24, Ed. 247, Art. 1634, Dezembro, 2013.

concentrações destas nos alimentos, os autores concluíram que a CIA e a FDN indigestível estimaram mais corretamente o volume de fezes do que a CIDA.

\subsection{Alcanos}

O uso de componentes indigestíveis das plantas como indicadores internos em animais em pastejo é um bom método para se estimar o consumo e a digestibilidade. Os alcanos são hidrocarbonetos alifáticos saturados das ceras da cutícula das plantas. Inicialmente o uso potencial dos n-alcanos como indicadores para determinação do consumo e digestibilidade de forragens foi proposto por (MAYES et al. 1986).

Os n-alcanos das plantas são encontrados na cera cuticular que geralmente é uma mistura complexa de lipídios alifáticos sintetizados pela planta (DOVE \& MAYES, 2005, 2006). São compostos orgânicos de cadeia aberta formados por carbono e hidrogênio, onde a diferença entre dois membros sucessivos da série é constante (são homólogos), e onde há o prefixo $n$ (normal) para os diversos alcanos, por maiores que sejam as moléculas, desde que os átomos de carbono se encontrem em cadeia contínua sem ramificações ( OLIVEIRA, 2003; OLIVEIRA \& PRATES, 2000).

Os n-alcanos internos são constituídos de cadeias de carbonos ímpares, de 25 a 35 carbonos $\left(\mathrm{C}_{25}-\mathrm{C}_{35}\right)$. As primeiras quatro substâncias da família são gases ( $C_{1}$ a $\left.C_{4}\right)$, os treze seguintes são líquidos $\left(C_{5}\right.$ a $\left.C_{17}\right)$ e os que contêm 18 ou mais átomos são sólidos. Destes, os que possuem 20 ou mais átomos de carbono, são, também, chamados de parafinas, sendo $C_{29}, C_{31}$ e $C_{33}$ os mais abundantes (DOVE \& MAYES, 2006). A digestibilidade aparente das dietas é obtida a partir da concentração do n-alcano interno na dieta e nas amostras de fezes, seguindo o mesmo procedimento utilizado com outros indicadores internos (FUKUMOTO, 2004).

Estudando ovinos recebendo dieta de azevém (Lolium multiflorum) e trevo branco (Trifolium repens), Mayes \& Lamb (1984) sugeriram que os nalcanos de cadeia longa poderiam ser úteis como indicadores para determinar 
MOURA, A.K.B. et al. Uso de indicadores nos estudos da nutrição animal. PUBVET, Londrina, V. 7, N. 24, Ed. 247, Art. 1634, Dezembro, 2013.

a digestibilidade de forragens. Esses autores concluíram, também, que houve um progressivo aumento na recuperação fecal, conforme aumentou o comprimento da cadeia carbonada dos $n$-alcanos, sendo a recuperação do $C_{35}$ de $97,5 \%$. Fukumoto et al. (2007) num experimento para estimar por meio de n-alcanos o consumo e digestibilidade da matéria seca de fenos de Braquiária decumbens e amendoim forrageiro demonstrou que houve efeito linear $(P<0,05)$ do aumento da cadeia carbônica dos $n$-alcanos sobre a recuperação fecal.

O uso dos alcanos em comparação aos outros indicadores tem como vantagem conhecer os resultados pela associação de dois indicadores (externo e interno) em um mesmo procedimento analítico (MAYES et al., 1986). Entretanto o fato de não ser fabricado no Brasil tem provocado limitações econômicas em seu uso (CARVALHO et al., 2007).

Testes experimentais de avaliação de consumo utilizando alcanos em comparação com outros indicadores têm mostrado aparentemente vantagens quando se leva em consideração a eficiência da resposta. Neste sentido, Dove e Mayes (1996) apresentaram um levantamento sobre o consumo em bovinos e ovinos em diversas condições de alimentação, demonstrando a eficiência da técnica dos alcanos, onde em onze situações experimentais, observou uma discrepância média de $1,165 \%$ para mais ou para menos em relação ao valor real.

Em razão da inaplicabilidade de alguns $n$-alcanos, Côrtes et al. (2005) alertam sobre a importância de se realizar mais estudos sobre o conjunto de $n$ alcanos capazes de permitir respostas mais acuradas em nossas condições. Em condições de pastejo com presença de múltiplas forrageiras, a aplicação da técnica requer o conhecimento preliminar do perfil dos $n$-alcanos das principais espécies consumidas pelos animais (SHU et al., 2008). 
MOURA, A.K.B. et al. Uso de indicadores nos estudos da nutrição animal. PUBVET, Londrina, V. 7, N. 24, Ed. 247, Art. 1634, Dezembro, 2013.

\section{INDICADORES EXTERNOS}

Uma substância adicionada à dieta como marcador é conhecida como marcador externo. Pode ser usado para estudo da digestibilidade, quando adicionado em nível constante; ou para estudo sobre taxas de passagem e fluxo da digesta, quando adicionado em doses variadas. $O$ marcador externo deve ser recuperado completamente nas fezes (logo, deve ser indigestível) e não poder ser absorvido pelas paredes do trato digestivo. Além disso, não deve afetar o animal ou a digestibilidade do alimento, e deve estar ausente do alimento e do solo (SALMAN, 2010).

\section{1 Óxido de cromo}

Entre os indicadores externos existentes, o óxido crômico é o mais empregado, apresentando as vantagens de ser barato e facilmente incorporado à dieta. Contudo, vários problemas têm sido correlacionados ao seu uso, como incompleta mixagem com a digesta ruminal, passagem mais rápida pelo rúmen que o material fibroso e possibilidade de acúmulo em alguma parte do trato digestivo e, dificuldades na análise (MACHADO et al.,2011).

O seu emprego é bastante difundido e tem sido o indicador mais amplamente utilizado para a estimativa da produção fecal, principalmente em ensaios de pastejo, pois permite, ainda, a estimava do consumo de forragem por meio da relação entre a produção fecal e a indigestibilidade da dieta (ASTIGARRAGA, 1997). O óxido crômico também possibilita estimar fluxo de matéria seca e matéria orgânica no aparelho digestório para posteriores inferências sobre o fluxo de proteína microbiana no duodeno, assim como sobre a partição da digestão dos nutrientes da dieta (FREGADOLLI, 2000). Suas vantagens residem no fato de não ser oneroso e na facilidade de incorporação à dieta e análise, somado à acurácia e precisão da técnica (MERCHEN, 1988). 
MOURA, A.K.B. et al. Uso de indicadores nos estudos da nutrição animal. PUBVET, Londrina, V. 7, N. 24, Ed. 247, Art. 1634, Dezembro, 2013.

O óxido de cromo foi amplamente utilizado nos trabalhos sobre estimativa de consumo a pasto. Segundo Saliba (1998), o indicador é fornecido aos animais em cápsulas de papel, diretamente no rúmen com o auxílio de um lança bolos durante 10 a 12 dias objetivando gerar uma concentração de equilíbrio e uniformemente distribuída no trato digestivo. A estimativa da excreção fecal é feita a partir das informações dos valores de concentração do indicador nas amostras fecais. Aliado às variações pontuais de excreção, dúvidas sobre o número de coletas diárias, o número total de coletas, intervalos entre coletas, quantidade do indicador fornecido, períodos de adaptação, etc. são objetivos de inúmeros trabalhos (BARROS et al., 2007).

Prigge et al. (1981) utilizaram o óxido crômico e outros indicadores externos na estimativa da excreção fecal em comparação com a colheita total das fezes em vacas de leite estabuladas. Os autores concluíram que o óxido crômico fornecido em duas doses diárias de $5 \mathrm{~g}$ cada durante doze dias (sete dias para adaptação e cinco dias de colheita) foi um método eficiente na estimativa da produção fecal. Detmann et al. (2001) compararam a aplicação de $\mathrm{Cr} 2 \mathrm{O} 3$ em duas doses de $5 \mathrm{~g}$ com uma única aplicação de $10 \mathrm{~g}$ por dia em animais a pasto. De acordo com os resultados de consumo e desempenho dos animais, concluíram que a aplicação de uma dose foi mais coerente com os resultados, sendo que a aplicação em duas doses teria superestimado o consumo a pasto.

Da mesma forma Oliveira et al. (2004) estudaram a curva diária de recuperação do óxido crômico fornecido uma vez ao dia na quantidade de $10 \mathrm{~g}$ e observaram que a redução dos períodos de adaptação de sete para cinco dias e de coleta de cinco para três dias forneceram dados confiáveis, aproximando-se do valor obtido pela recomendação de Prigge et al. (1981).

Soares et al. (2004) compararam o consumo de matéria seca medida entre as diferenças de peso do alimento oferecido e das sobras e o estimado pelo óxido crômico em vacas mestiças Holandês-Zebu, verificando-se superestimação média de $9,25 \%$ pelo óxido crômico. Apesar disto os autores 
MOURA, A.K.B. et al. Uso de indicadores nos estudos da nutrição animal. PUBVET, Londrina, V. 7, N. 24, Ed. 247, Art. 1634, Dezembro, 2013.

concluíram ter sido satisfatório o uso do óxido crômico e que as diferenças foram resultantes da recuperação fecal do indicador nas fezes.

$\mathrm{O}$ uso do $\mathrm{Cr}_{2} \mathrm{O}_{3}$ misturado em alimento concentrado tem a vantagem de diminuir o estresse causado aos animais durante o fornecimento do indicador. Entretanto, em função de sua baixa palatabilidade, a inclusão de $5 \%$ de $\mathrm{Cr}_{2} \mathrm{O}_{3}$ no concentrado, como recomendado por Penning (2004), tem limitado sua utilização a animais dotados de cânula ruminal (RIBEIRO FILHO et al., 2003).

\subsection{Dióxido de titânio}

O dióxido de titânio $\left(\mathrm{TiO}_{2}\right)$ é insolúvel em água e ácidos diluídos, não sendo absorvido pelas plantas (Marais, 2000). É um pó de coloração branca, sem odor ou gosto. Titgemeyer et al. (2001) demonstraram que o dióxido de titânio pode ser utilizado como indicador externo, em alternativa ao óxido crômico, em estudos de digestão e pode ser adicionado legalmente ao alimento em quantidades que não excedam $1,0 \%$ do produto final (Ferreira et al., 2009). Ademais, segundo Valadares Filho et al. (2006), outra vantagem competitiva do $\mathrm{TiO}_{2}$ diz respeito ao seu custo, relativamente menor do que o óxido crômico.

Ferreira et al. (2009), ao utilizarem o indicador dióxido de titânio e outros indicadores externos e internos, em novilhas alimentadas com cana-deaçúcar para avaliarem a digestibilidade dos nutrientes observaram que o mesmo apresentou valores semelhantes à coleta total de fezes. Esses mesmos autores ao realizarem outro experimento com vacas em lactação, alimentadas com silagem de milho e concentrado e utilizando os indicadores acima, encontraram comportamento semelhante para os dados obtidos para o dióxido de titânio e a coleta total de fezes. Marcondes et al. (2006), em estudo com novilhas mestiças alimentadas com cana-de-açúcar e concentrado, também não verificaram diferença no consumo individual de concentrado estimado por meio do óxido crômico e do dióxido de titânio em comparação ao consumo observado. 
MOURA, A.K.B. et al. Uso de indicadores nos estudos da nutrição animal. PUBVET, Londrina, V. 7, N. 24, Ed. 247, Art. 1634, Dezembro, 2013.

Glindemann et al. (2009), ao avaliarem a produção fecal e a taxa de recuperação fecal do dióxido de titânio em ovelhas a pasto, encontraram resultados satisfatórios para os parâmetros citados acima e recomendaram a aplicação desse indicador duas vezes ao dia. Os resultados obtidos com o dióxido de titânio confirmam os verificados por Titgemeyer et al. (2001), que demonstraram que esse indicador pode ser utilizado em estudos de consumo em ruminantes, constituindo uma alternativa de indicador para estudos de digestão.

\subsection{Lignina isolada, purificada e enriquecida (LIPE)}

Caracterizado como hidroxifenilpropano modificado e enriquecido, o LIPE $®$ é um indicador externo de digestibilidade desenvolvido especificamente para pesquisas (FIGUEREDO, 2011).

Em 2002, pesquisadores da EV-UFMG começaram a trabalhar a molécula da lignina, no sentido de otimizar a sua determinação nas fezes. Saliba et al. (2003) isolaram a lignina e a enriqueceram com grupamentos não comumente encontrados na lignina da dieta animal, originando o LIPE $^{\circledR}$. O LIPE $^{\circledR}$ foi inicialmente utilizado em estudo de consumo e digestibilidade comparada à coleta total de fezes em coelhos. As estimativas de produção fecal e digestibilidade revelaram a eficiência do LIPE $^{\circledR}$ como indicador externo, não apresentando diferenças estatísticas com relação à coleta total. Além disso, apresentou as vantagens de um curto período de adaptação e ser de baixo custo.

Oliveira et al. (2004) compararam os dados de consumo estimados pela LIPE $^{\circledR}$ e pelo óxido crômico em novilhos nelore a pasto. Os indicadores foram fornecidos individualmente via sonda esofágica em dose única, momento em que foi realizada a coleta de fezes. A curva apresentada da recuperação dos indicadores e da excreção fecal demonstrou que a LIPE $^{\circledR}$ atingiu a concentração de equilíbrio em menor período (três dias) e que ambos os indicadores estimaram de forma eficiente o consumo. 
MOURA, A.K.B. et al. Uso de indicadores nos estudos da nutrição animal. PUBVET, Londrina, V. 7, N. 24, Ed. 247, Art. 1634, Dezembro, 2013.

Estudos conduzidos com o objetivo de investigar a capacidade do LIPE $^{\circledR}$ na estimativa da digestibilidade, da produção fecal e do consumo em diferentes espécies animais, como aves, suínos, eqüinos e bovinos, demonstraram que o LIPE $^{\circledR}$ assemelha-se às ligninas de madeiras duras, sendo totalmente recuperado nas fezes sem modificações, digestão ou absorção (Vasconcelos et al., 2007). Além disso, o LIPE $^{\circledR}$ não apresenta variação diurna de excreção nas fezes, possibilitando que o seu fornecimento e a amostragem das fezes sejam feitos uma vez ao dia (Rodriguez et al., 2006). Esses estudos revelaram que 0 LIPE $^{\circledR}$ apresenta propriedades físico-químicas bastante estáveis e uma grande consistência químico-estrutural.

Oliveira et al. (2005) compararam o LIPE $^{\circledR}$ e o óxido crômico em bovinos Nelore fistulados no esôfago, nas estimativas de excreção fecal e consumo voluntário em pastagens de Marandu (Brachiaria brizantha cv.), comparando ainda diferentes períodos de adaptação para os dois indicadores, (três e sete dias). O consumo estimado de matéria seca foi de 2,$12 ; 2,09 ; 2,16$ e 2,10\% respectivamente, do peso vivo para os tratamentos com óxido crômico ou LIPE $^{\circledR}$ para três ou sete dias, respectivamente, não se observando diferenças estatísticas entre os mesmos ( $P>0,05)$. Quanto aos períodos de adaptação, três dias foram suficientes para estabilizar a concentração dos indicadores nas fezes dos animais. O LIPE $^{\circledR}$ foi capaz de estimar com sucesso a excreção fecal e o consumo de bovinos de corte criados a pasto.

\subsection{Lantanídeos (terras raras)}

Esses indicadores são usados principalmente para estimativas de trânsito ou fluxo, marcando a fase sólida, ou a fase líquida. Ellis (1968) relata inúmeras propriedades das terras raras, e sugere vantagens no seu uso como indicador. Esses elementos têm afinidade pela parede celular das plantas e são empregados no estudo da taxa de passagem da digesta em ruminantes, sendo considerados adequados indicadores de fluxo de resíduos indigestíveis (Ellis et al., 2002). 
MOURA, A.K.B. et al. Uso de indicadores nos estudos da nutrição animal. PUBVET, Londrina, V. 7, N. 24, Ed. 247, Art. 1634, Dezembro, 2013.

Pond et al. (1989) avaliaram o comportamento dos elementos "terras raras" Itérbio (Yb), Térbio ( $\mathrm{Tb})$, Cromo (Cr), Samário (Sm), Lantânio (La) e Lutécio (Lu) sobre os parâmetros do fluxo da fase sólida. Os resultados mostraram características de passagem similares entre os elementos nas primeiras 24 horas, o que permitiria o uso conjunto de dois marcadores.

O itérbio (Yb) vem sendo um dos mais utilizados (SALIBA, 1998). Entretanto, Crooker et al. (1982) observaram solubilização do itérbio sob condições ácidas do abomaso. Segundo Owens \& Hanson (1992), ocorre variação diurna na concentração de indicador, porém a concentração fecal de itérbio tem sido constante durante 24 horas de amostragem, representando uma vantagem na sua utilização.

A disponibilidade do método de análise, dita se o indicador será utilizado, sendo os resultados dependentes do método de análise empregado (SALIBA, 1998). A Espectrofotometria de Absorção Atômica (EAA) é o procedimento tipicamente empregado para determinar baixas concentrações de metais, portanto é a técnica utilizada para dosar Yb nas fezes de animais. Sabe-se que essa técnica é satisfatória, sendo o uso do Yb recomendado por (PRIGGE et al., 1981; BERCHIELLI et al., 1998).

\section{CONSIDERAÇÕES FINAIS}

O uso de indicadores é uma opção válida para determinar a produção fecal de animais, e assim estimar o consumo e digestibilidade sendo cada vez mais utilizados em substituição ao método de coleta total de fezes. É possível afirmar que, todos os indicadores possuem limitações, porém sua variabilidade é extensa e atende à demanda para estimativas dos vários parâmetros determinados em ensaios de nutrição. A escolha de um indicador deve ser baseada na sua taxa de recuperação fecal, validada em ensaios de coleta total de fezes e ao seu custo.

Estabelecer critérios que forneçam subsídios para escolha do indicador mais adequado é ponto primordial na decisão pelo seu uso, estando entre eles: 
MOURA, A.K.B. et al. Uso de indicadores nos estudos da nutrição animal. PUBVET, Londrina, V. 7, N. 24, Ed. 247, Art. 1634, Dezembro, 2013.

fácil aplicação, recuperação adequada de acordo com a dieta utilizada, custos e facilidade na análise. Desta forma, aumenta-se a confiabilidade das estimativas desejadas, fornecendo resultados que possibilitem o maior detalhamento em estudos de avaliação de alimentos.

\section{REFERÊNCIAS}

ANDRIGUeTtO, J. M.; PERLY, L.; MINARDI, I.; GEMAEL, A.; FLEMMING, J. S.; SOUZA, G. A. de; BONA FILHO, A. Nutrição animal: as bases e os fundamentos da nutrição animal - os Alimentos, Vol. I, São Paulo:Nobel, 1982. 395 p.

ASTIGARRAGA, L. Técnicas para la medición del consume de rumiantes em pastoreo. In:SIMPÓSIO SOBRE AVALIAÇÃO DE PASTAGENS COM ANIMAIS, 1997, Maringá. Anais...Maringá: UEM, 1997. p.1-23.

BARROS, E. E. L.; FONTES, C. A. A.; DETMANN, E.; VIEIRA, R. A. M.; HENRIQUES, L. T.; RIBEIRO, E. G. Avaliação do perfil nictemeral de excreção de indicadores internos e de óxido crômico em ensaios de digestão com ruminantes. Revista Brasileira de Zootecnia, Viçosa, MG, v. 36, n. 6, p. 2102-2108, 2007. Suplemento.

BERCHIELLI, T. T. RODRIGUEZ, N.M.; OSÓRIO NETO, E.; ROCHA, S.S. Comparação de indicadores de fase sólida para medir fluxo de matéria seca e matéria orgânica no duodeno.

Arq. Bras. Vet. Zootec. v. 50, n. 2, p.147-152, 1998

BERCHIELLI, T. T.; ANDRADE, P.; FURLAN, C. L. Avaliação de indicadores internos em ensaios de digestibilidade. Rev. Bras. Zootec. v. 29, n. 3, p. 830-833, 2000.

BERGERO, D.; MIRAGLIA, N.; ABBA, C.; POLIDORI, M.. Apparentof digestibility mediterranean forages determined by total collection of faeces and acid-insoluble ash as internal marker. Livest. Prod. Sci. v. 85, n. 2-3, p. 235-238, 2004.

CARVALHO, P. C. F.; KOZLOSKI, G. V.; RIBEIRO FILHO, H. M. N.; REFFATTI, M. V.; GENRO, T. C. M.; EUCLIDES, V. P. B. Avanços metodológicos na determinação do consumo de ruminantes em pastejo. Revista Brasileira de Zootecnia, Viçosa, MG, v. 36, p. 151-170, 2007. Suplemento especial.

COCHRAN, R. C.; Adams, D.C.; Wallace, D.; Galyean, M.L. Predicting digestibility of different diets with internal markers: evaluation of four potential markers. Journal Animal Science, $v$. 63, n. 5, p. 1476-1483, 1986.

COLLET, S.G. Métodos de pesquisa em nutrição de ruminantes: indicadores de índice fecal, Nalcanos e fibra em detergente ácido para estimativa do consumo e/ou fluxo intestinal de nutrientes. Lages-SC, 2011. 76p. Dissertação (Mestrado) - Universidade do Estado de Santa Catarina, 2011.

CROOKER, B. A.; CLARK, J. H.; SHANKS, R. D. Rare earth elements as markers for rate of passage measurements of individual feedstuffs through the digestive tract of ruminants. J. Nutr. v. 112, n. 7, p. 1353-1361, 1982. 
CÔRTES, C.; DAMASCENO, J. C.; PAINE, R. C.; FUKUMOTO, N. M.; RÊGO, F. C. de A.; CECATO, U. Uso de n-alcanos na estimativa da composição botânica em amostras com diferentes proporções de Brachiaria brizantha e Arachis pintoi. Revista Brasileira de Zootecnia, Viçosa, MG, v. 34, n. 5, p. 1468-1474, 2005.

DETMANN, E.; VALADARES FILHO, S.C.; PAULINO, M.F.; ZERVOUDAKIS, J.T.; EUCLYDES, R.F.; LANA, R.P.; QUEIROZ, D.S. Cromo e indicadores internos na determinação do consumo de novilhos mestiços, suplementados, a pasto. Revista Brasileira de Zootecnia, v.30, n.5, p.1600-1609, 2001.

DOVE, H., MAYES, R.W. Using n-alkanes and other plant wax components to estimate intake, digestibility and diet composition of grazing/browsing sheep and goats. Small Ruminant Research, v.59, p. 123-139, 2005.

DOVE, H., MAYES, R.W. Protocol for the analysis of n-alkanes and other plant-wax compounds and for their use as markers for quantifying the nutrient supply of large mammalian herbivores. Nature Protocol, Vol. 1, n. 4, p. 1680-1697, 2006.

ELLIS, W. C. Dysprosium as an indigestible marker and its determination by radioactivation analysis. J. Agric. Food Chemists, v. 16, n. 2, p. 220-228, 1968.

ELLIS, W. C.; WYLIE, M. J.; MATIS J. H. Validity of specifi cally applied rare earth elements and compartmental models for estimating flux of undigested plant tissue residues through the gastrointestinal tract of ruminants. J. Anim. Sci. v. 80, n. 8, p. 2753-2758, 2002.

FAHEY, G. C. \& JUNG, H. G. Lignin as a marker in digestion studies - a review. Journal Animal Science, v. 57, n. 1, p. 220-225, 1983.

FERRET, A.; PLAIXATS, J.; CAJA, G.; GASA, J.; PRIÓ, P. Using markers to estimate dry matter digestibility, faecal output and dry matter intake in dairy ewes fed italian ryegrass hay or alfalfa hay. Small Ruminant Res. v. 33, n. 2, p. 145-152, 1999.

FERREIRA, M. de A.; VALADARES FILHO, S. de C.; MARCONDES, M. I.; PAIXÃO, M. L.; PAULINO, M. F.; VALADARES, R. F. D. Avaliação de indicadores em estudos com ruminantes: digestibilidade. Revista Brasileira de Zootecnia, Viçosa, MG, v. 38, n. 8, p. 1568-1573, 2009.

FIGUEREDO, M.R.P. Indicadores externos de digestibilidade aparente em ovinos. 1998. $236 \mathrm{f}$. Dissertação (Mestrado em Zootecnia)- Escola de Veterinária da UFMG, Belo Horizonte, 2011.

FONNESBECK, P.V. Digestion of soluble and fibrous carbohydrate of forrage by horse Journal Animal Science, 7(6):1336-1344, 1968.

FONTES, C. A. A.; OLIVEIRA, M. A T.; LANA, R. P. Avaliação de indicadores na determinação da digestibilidade em novilhos. Rev. Soc. Bras. Zootec. v. 2, n. 2, p. 529-539, 1996.

FREGADOLLI, F. L. Efeito das fontes de amido e nitrogênio de diferentes degradabilidades ruminais sobre o pH e concentração de amônia no líquido ruminal e efi ciência de síntese microbiana. 2000. 69 f. Dissertação (Mestrado em Zootecnia)- Universidade Estadual de Maringá, Maringá, 2000.

FUKUMOTO, N.M. Uso de n-alcanos para estimar o consumo da matéria seca e composição da dieta em ovinos alimentados com fenos de Brachiaria decumbens e Arachis pintoi. 2004. 50p. Dissertação (Mestrado em Zootecnia). Maringá: Universidade Estadual de Maringá, 2004. 
FUKUMOTO, N. M., DAMASCENO, J.C, CÔRTES, C.; PAINE, R.C.; QUEIROZ, M.F.S; SANTOS, G.T.; MAKOTO MATSUSHITA, M. Consumo e digestibilidade da matéria seca de fenos de braquiária decumbens e amendoim forrageiro em ovinos estimados por meio de $n$-alcanos.

Revista Brasileira de Zootecnia, v.36, n.2, p.471-479, 2007.

GLIDEMANN, T.; TAS, B.M.; WANG, C.; ,ALVERS, S.; SUSENBETH, S. Evaluation of titanium dioxide as an inert marker for estimating faecal excretion in grazing sheep. Animal Feed Sciense and Technology, v.152, p. 186-197, 2009.

ÍTAVO, L. C. V, VALADARES FILHO, S. C., SILVA, F. F.; VALADARES, R.F.D.; PAULINO, M.F.; ÍTAVO, C.C.B.F.; MORAES, E.H.B.K. Comparação de indicadores e metodologia de coleta para estimativas de produção fecal e fluxo de digesta em ovinos. Revista Brasileira de Zootecnia,v. 31, n. 4, p. 1833-1839, 2002a.

ÍTAVO, L. C. V.; VALADARES FILHO, S.C.; SILVA, F.F.; VALADARES, R.F.D.; PAULINO, M.F.; ÍTAVO, C.C.B.F.; MORAES, E.H.B.K. Comparação de indicadores e metodologia de coleta para estimativas de produção fecal e fluxo de digesta em bovinos. Rev. Bras. Zootec. v. 31, n. 4, p. 1833-1839, 2002b.

JONE, L.H.P. \& HADRECK, K.A. The relation between the silica content of the diet and the excretion of silica by sheep. Journal of Agricultural Science, Cambridge, v.65, p.129-134, 1965.

KING, E.J.; STACY, B.D.; HOLT, P.F.; YATES, D.M.; PICKLES, D. The colorimetric determination of silicon in the micro-analysis of biological material and mineral dusts. Analyst, London, v.80, p. $441-453,1955$.

KOTB, A. R.; LUCKEY, T. D. Markers in nutrition. Nutr. Abstr. Rev. v. 42, n. 3, p. 813-845, 1972.

LIPPKE, H.; ELLIS, W. C.; JACOBS, B. F. Recovery of indigestible fiber from feces of sheep and cattle on forage diets. Journal of Dairy Science, v. 69, p.403-412, 1986.

MACHADO, H.M. Efeitos de diferentes combinações de capim-elefante (Pennisetum purpureum, Schum): cana-de-açúcar. (Saccharum officinarum, L.) sobre a digestibilidade em eqüinos, utilizando diferentes metodologias de determinação. Viçosa, MG: UFV, 1992. 71p. Dissertação (Mestrado em Zootecnia) - Universidade Federal de Viçosa, 1992.

MACHADO, A.S.; GODOY, M.M.; LIMA, M.L.M.; FARIA JÚNIOR, O.L.; MORGADO, H.S.; ARAÚJO, E.P. Utilização de óxido crómico e LIPE ${ }^{\circledR}$ como indicadores externos na estimativa de digestibilidade em ruminantes. PUBVET, Londrina, V. 5, N. 20, Ed. 167, Art. 1124, 2011.

MARCONDES, M.I.; VALADARES FILHO, S.C.; BRITO, A.F. et al. Uso de diferentes indicadores para estimar a produção de matéria seca fecal e avaliar o consumo individual de concentrado e volumoso em novilhas. In: REUNIÃO ANUAL DA SOCIEDADE BRASILEIRA DE ZOOTECNIA, 43., 2006, João Pessoa. Anais... João Pessoa: Sociedade Brasileira de Zootecnia, 2006. p.1-5.

MARAIS, J. P. Use of markers. In: $D^{\prime}$ MELLO, J. P. F. (Ed.) Farm animal metabolism and nutrition. Wallingford: CAB International, 2000, p. 255-277.

MAURÍCIO, R.M. Determinação da digestibilidade aparente em eqüideos através do óxido crômico, da lignina e da coleta total das fezes. Belo Horizonte, MG: UFMG, 1993. 62p. Dissertação (Mestrado em Zootecnia) - Universidade Federal de Minas Gerais, 1993. 
MAYES, R. W.; LAMB, C. S.; COLGROVE, P. M. The possible use of $n$-alkanes in herbage as indigestible faecal markers. In: GENERAL MEETING EUROPEAN GRASSLAND FEDERATION, 1984, Proceedings... Nutrition Society, v. 43, n. 1-3, p. 39, 1984.

MAYES, R. W; LAMB, C. S.; COLGROVE, P. M. The use of dosed and herbage n-alcanes as markers for the determination of herbage intake. J. Agric. Sci. v. 107, n. 1, p. 161-170, 1986.

MERCHEN, N. R. Digestion, absorption and excretion in ruminants. In: D. C. CHURCH. The ruminant animal digestive physiology and nutrition. Prentice-Hall, Englewood Cliffs, NJ, 1988. p. $172-201$.

MUNTIFERING, R.B. Evaluation of various lignin assays for determining ruminal digestion of roughages by lambs. Journal Animal Science, 55(2):432-438, 1982.

OLIVEIRA, D.E., PRATES, E.R. Utilização dos componentes da cera das plantas, em especial os n-alcanos, em estudos de nutrição de ruminantes. Ciência Rural, Santa Maria, v. 30, n. 3, p. 549-557, 2000.

OLIVEIRA, D.E. Uso da técnica de alcanos para medir o aporte de nutrientes através de estimativas do consumo de forragem em bovinos. 2003. 129 p. Tese (Doutorado em Agronomia). Escola Superior de Agricultura "Luiz de Queiroz", Piracicaba. 2003.

OLIVEIRA JUNIOR, R. C.; PIRES, A.V.; FERNANDES, J.J.R.; SUSIN, I.; SANTOS, F.A.P.; NASCIMENTO FILHO, V.F.; ARAÚJO, R.C. Avaliação de indicadores para estimar a digestibilidade dos nutrientes em novilhos nelore alimentados com dietas contendo alto teor de concentrado e fontes nitrogenadas. R. Bras. Zootec. v. 33, n. 3, p. 749-758, 2004.

OLIVEIRA, A.P.; SALIBA, E.O.S.; BORGES, I.; AROEIRA, L.J.M.; GONTIJO NETO, M.M.; AMARAL, T.B. Concentração de óxido crômico e LIPE nas fezes de bovinos em pastagem de Brachiaria brizantha utilizadas nas estimativas de consumo. In: 42a REUNIÃO ANUL DA SOCIEDADE BRASILEIRA DE ZOOTECNIA, 2005, Goiania. Anais... 42a reunião anual da SBZ. Goiania, 2005.

OLIVEIRA, L.O.F.; SANTOS, S.A.; ABREU, U.G.P.; CRISPIM, S.M.A.; NOGUEIRA, E. Uso de Indicadores nos Estudos de Nutrição Animal Aplicados aos Sistemas de Produção a Pasto. Corumbá : Embrapa Pantanal, 2012 (Documentos 120). Disponível em: < http://www.cpap.embrapa.br/publicacoes/online/DOC120.pdf> Acessado em 31 de maio de 2013.

OWENS, F. N.; HANSON, C. F. External and internal markers for appraising site and extent of digestion in ruminants. Journal Dairy Science, v. 75, n. 9, p. 2605-2617, 1992.

PENNING, P. D. Animal-based techniques for estimating herbage intake. In: PENNING P. D. (Ed). Herbage Intake Handbook. 2ed. Reading: The British Grassland Society, 2ed. P.53-94, 2004.PIAGGIO, L. M. et al. Avaliação das cinzas insolúveis em ácido, fibra detergente ácido indigestível e lignina em detergente ácido indigestível como indicadores internos da digestibilidade. Rev. Soc. Bras. Zootec. v. 20, n. 3, p. 306 312, 1991.

PEREIRA, J.C, GARCIA, J.A., COELHO DA SILVA, J.F. et al. 1983. Estudos de digestão em bovinos fistulados, alimentados com rações tratadas com formaldeído e contendo óleo. II. Métodos para estimativa da excreção de matéria seca fecal. R. Soc. Bras. Zootec., 12(3):429-439. 
PRIGGE, E. C.; VARGA, G.A.; VICINI, J.L.; REID, R.L. Comparison of ytterbium chloride and chromium sesquioxide as fecal indicators. J. Anim. Sci. v. 53, n. 6, p. 1629-1633, 1981.

POND, K, R.; ELLIS, W. C.; MATIS, J. H.; DESWYSEN, A. G. Passage of chromium-mordanted and rare earth-labeled fiber: time of dosing kinetics. Journal of Animal Science, Champaign, v. 67, n. 4, p. 1020-1028, 1989.

RIBEIRO FILHO, H.M.N.; DELAGARDE, R.; PEYRAUD, J.L. Inclusion of white clover in stripgrazed perennial ryegrass swards: herbage intake and milk yield of dairy cows at different ages of sward regrowth. Animal Science, v.77, p.499-510, 2003.

RODRÍGUEZ, N. M.; SALIBA, E. O. S.; GUIMARÃES JÚNIOR, R. Uso de indicadores para a estimativa de consumo a pasto e digestibilidade. In: $43^{\circ}$ Reunião anual da Sociedade Brasileira de Zootecnia, 43, 2006. João Pessoa. Anais.... João Pessoa, SBZ, 2006, p.263-282.

SALIBA, E. O. S. Caracterização química e microscópica das ligninas dos resíduos agrícolas de milho e de soja expostos à degradação ruminal e seu efeito sobre a digestibilidade dos carboidratos estruturais. 1998. 236 f. Tese (Doutorado em Ciência Animal)- Escola de Veterinária da UFMG, Belo Horizonte, 1998.

SALIBA, E. de O. S.; RODRIGUEZ, N. M.; PILÓ-VELOSO, D.; GONÇALVES, L. C.; BORGES, I. Utilização da lignina isolada da palha de milho como indicador de digestibilidade. In: REUNIÃO ANUAL DA SOCIEDADE BRASILEIRA DE ZOOTECNIA, 36.,1999, Porto Alegre. Resumos... Porto Alegre: Sociedade Brasileira de Zootecnia, 1999. p. 145-147.

SALIBA, E. O. S.; RODRIGUEZ, N. M.; PILÓ-VELOSO, D. Utilization of purified lignin extracted from Eucalyptus grandis (PELI), used as an external marker in digestibility trials in various animal species. In: WORLD CONFERENCE ON ANIMAL PRODUCTION, 9. 2003, Porto Alegre. Proceedings... Porto Alegre, 2003.

SALMAN, A.K.D.; FERREIRA, A.C.D.; SOARES, J.P.G.; Metodologias para avaliação de alimentos para ruminantes domésticos Porto Velho, (Documento 136), RO: Embrapa Rondônia, $2010 . \quad$ Disponível em: < http://www.cpafro.embrapa.br/media/arquivos/publicacoes/doc136_alimentacaoderuminantes. pdf> Acessado em 31 de maio de 2013.

SHERROD, L. B.; SUMMERS, C.B.; ALBIN, R.C.; RATCLIFF, R.K. ADF Insoluble ash, HCl Insoluble ash, and lignin as indicator for determining ruminant digestibility. American Society of Animal Science Western Section, . v. 29, n. 5, p. 236-242, 1978.

SHU, B.; LIN, L.; ZHANG, Y.; WANG, H.; LUO, H. N-alkane profiles of common rangeland species in northern China and the influence of drying method on their concentrations. Canadian Journal of Plant Science, Ottawa, v. 88, n. 1, p. 137-141, 2008.

SOARES, J. P. G.; BeRCHIELLI, T. T.; AROEIRA, L. J. M.; DERESZ, F.; VeRNeQUe, R. da S. Estimativas de consume do capim-elefante (Pennisetum purpureum Schum), fornecido picado para vacas lactantes utilizando a técnica do óxido crômico. Revista Brasileira de Zootecnia, Viçosa, MG, v. 33, n. 3, p. 811-820, 2004.

STREETER, C. L. A review of techniques used to estimate the "in vitro" digestibility of grazed forage. Journal Animal Science, v. 29, n. 5, p.757- 768, 1969.

SUTTON, E.I., BOWLAND, J.P., McCARTHY, J.F. 1977. Sudies with horses comparing 4N-HCl insoluble ash as index material with total fecal collection in the determination of apparent digestibilities. Canad. J. Anim. Sci., 57:543-549. 
THONEY, M. L.; DUHAIME, D.J.; MOE, P.W.; REID, J.T. Acid insoluble ash and permanganate lignin as indicators to determine digestibility of cattle rations. Journal Animal Science, v. 49, n. 4, p. 1112-1116, 1979.

THONEY, M.L.; PALHOF, B.A.; DECARLO, M.R.; ROSS, D.A.; FIRTH, N.L.; QUAAS, R.L.; PEROSIO, D.J.; DUHAIME, D.J.; ROLLINS, S.R.; NOUR, A.Y.M. Sources of variation of dry matter digestibility measured by the acid insoluble ash marker. J. Dairy Sci. v. 64, n. 3, p. 661- 668, 1985.

TITGEMEYER, E.C.; ARMENDARIZ, C.K.; BINDEL, D.J. et al. Evaluation of titanium dioxide as a digestibility marker for cattle. Journal of Animal Science, v.79, n.4, p.1059-1063, 2001.

VALADARES FILHO, S.C.; MORAES, E.H.B.K.; DETMANN, E.; PAULINO, M.F.; VALADARES, R.F..D.; MORAES, K.A.K.; MARCONDES, M.I. Perspestivas do uso de indicadores para estimar o consumo individual de bovinos alimentados em grupo. In: REUNIÃO ANUAL DA SOCIEDADE BRASILEIRA DE ZOOTECNIA, 43., 2006, João Pessoa. Anais... João Pessoa: Sociedade Brasileira de Zootecnia, 2006. p.291-322.

VAN SOEST, P. J. Nutritional ecology of the ruminant. 2. ed. Ithaca: Cornell University, 1994. $476 \mathrm{p}$.

VASCONCELLOS, C.H.F.; VELOSO, J.A.F.; SALIBA, E.O.S. Uso da LIPE como indicador externo na determinação da energia metabolizável de alimentos em frangos de corte. Arquivo Brasileiro de Medicina Veterinária e Zootecnia, v.59, n.2, p.459-465, 2007.

WARNER, A. C. I. Rate of passage of digesta through the gut of mammals and birds. Nutr. Abstr. Rev. v. 51, p. 789-820, 1981.

ZEOULA, L. M.; PRADO, I. N. do; DIAN, P. H. M.; GERON, L. J. V.; CALDAS NETO, S. F. de; MAEDA, E. M.; DAL - PRA PERON, P.; MARQUES, J. de A.; FALCÃO, A. J. de S. Recuperação fecal de indicadores internos avaliados em ruminantes. Revista Brasileira de Zootecnia, Viçosa, MG, v. 31, n. 4, p.1856-1874, 2002. 
